\title{
Pengelolaan Pemangkasan Tanaman Teh (Camellia Sinensis (L.) O. Kuntze) di Karanganyar, Jawa Tengah
}

\section{Pruning Plant Management of Tea (Camelia sinensis (L.) O Kuntze) Karanganyar, Central Java}

\section{Martini Aji dan Supijatno*}

Departemen Agronomi dan Hortikultura, Fakultas Pertanian, Institut Pertanian Bogor (Bogor Agricultural University), Jl. Meranti, Kampus IPB Darmaga, Bogor 16680, Indonesia Telp. \& Faks.62-251-8629353 e-mail agronipb@indo.net.id *Penulis Korespondensi : supijatno@yahoo.com

\section{Disetujui 11 Mei 2015 / Published online 18 Mei 2015}

\begin{abstract}
The research aimed at studying the management aspects of pruning of tea plants in the field, both technical and managerial, improve job skills and gain work experience in the field. The research is done for four months from February to June 2011 in Karanganyar, Central Java. Method used is actively working with the following activities are carried out in the field, as well as primary and secondary data collection. Pruning is one of the activities to rejuvenate the tea plant cultivation by making the area a low quotation for ease of harvesting and increase crop productivity. pruning activities conducted at PT Rumpun Sari Kemuning is good enough, although there are some obstacles in the implementation in the field.

Keywords: implementation of pruning of tea, management pruning of tea, pruning condition of tea, pruning equipment, type of pruning

\section{ABSTRAK}

penelitian bertujuan untuk mempelajari aspek-aspek manajemen pemangkasan tanaman teh di lapangan, baik teknis dan manajerial, meningkatkan keterampilan kerja dan mendapatkan pengalaman kerja di lapangan. Penelitian dilaksanakan selama empat bulan dari Februari-Juni 2011 di Karanganyar, Jawa Tengah. Metode yang digunakan adalah metode kerja aktif dengan mengikuti kegiatan-kegiatan yang dilakukan di kebun, pengumpulan data primer dan data sekunder. Pemangkasan adalah salah satu kegiatan untuk meremajakan budidaya tanaman teh dengan membuat daerah petikan lebih pendek untuk kemudahan panen dan untuk meningkatkan produktivitas tanaman. kegiatan pemangkasan yang dilakukan di Karanganyar, Jawa Tengah cukup baik, meskipun ada beberapa kendala dalam pelaksanaan di lapangan.
\end{abstract}

Kata kunci: jenis pemangkasan, kondisi pemangkasan teh, manajemen pemangkasan teh, pelaksanaan pemangkasan teh, peralatan pemangkasan 


\section{PENDAHULUAN}

Teh (Camellia sinensis (L.) O. Kuntze) merupakan salah satu tanaman perkebunan yang juga diusahakan di wilayah Indonesia. Tanaman teh diperkirakan berasal dari daerah pegunungan Himalaya dan daerah yang berbatasan dengan China, India, dan Burma. Meskipun tanaman ini kalah saing dengan produksi tanaman perkebunan lain, namun tanaman ini juga menjadi salah satu penyumbang bagi devisa negara non migas pada sektor perkebunan.

Luas area perkebunan teh di Indonesia tahun 2009123506 ha, yang terdiri $46.25 \%$ perkebunan rakyat, $31.22 \%$ perkebunan besar negara, dan $22.52 \%$ perkebunan besar swasta. Luas area sementara pada tahun 2010, 124573 ha, sedangkan estimasi tahun 2011 seluas 123554 ha dengan masih disominasi perkebunan rakyat. Ekspor teh Indonesia mencapai 96209 ton dengan nilai US\$ 158958 pada tahun 2008 dan pada tahun 2009 mengalami penurunan hingga 92305 ton dengan nilai US\$ 171628 (Ditjenbun, 2011).

Prospek industri teh di pasar dunia semakin cerah dengan digalakkannya back to nature terhadap konsumsi makanan dan minuman di berbagai negara Asia dan Eropa. Daun teh muda mengandung Catechin dan Caffein, unsur kimia inilah yang menjadikan teh sebagai minuman yang dapat menyehatkan apabila diminum secara rutin dan teratur. Namun, potensi pasar ekspor yang terbuka luas ini tidak berarti hanya diperoleh Indonesia saja, tetapi juga beberapa negara produsen teh dunia lainnya seperti India, Sri Lanka dan Kenya. Menurut data dari FAO, Indonesia menempati peringkat ke tujuh negara produsen the setelah China, India, Kenya, Sri Lanka, Turki, dan Vietnam (FAO, 2008).

Pembudidayaan tanaman teh bertujuan untuk mendapatkan hasil produksi dalam bentuk daun (vegetatif). Untuk mendapatkan hasil yang tinggi dan berkesinambungan, fase vegetatif haruslah dipertahankan selama mungkin. Semakin panjang masa vegetatif tanaman teh, semakin panjang pula masa produksi tanaman tersebut. Untuk mempertahankan fase vegetatif dapat dilakukan dengan jalan pemangkasan. Pemangkasan merupakan salah satu kegiatan budidaya dalam pemeliharaan teh dengan menjadikan bidang petik rendah untuk memudahkan pemetikan. Ada beberapa tujuan pemangkasan, antara lain untuk membentuk bidang petik seluas mungkin guna merangsang pertumbuhan tunas-tunas baru, sehingga mampu menghasilkan pucuk yang banyak. Selain itu juga dapat menyehatkan tanaman dengan membuang bagian-bagian yang sudah rusak, baik akibat gangguan teknis maupun serangan hama penyakit yang dapat menghambat pertumbuhan tunastunas baru (Pusat Penelitian Teh dan Kina, 2006).

Kegiatan penelitian bertujuan untuk mempelajari aspek pengelolaan pemangkasan tanaman teh yang dilaksanakan di kebun, baik secara teknis maupun menejerial, meningkatkan keterampilan kerja dan memperoleh pengalaman kerja di lapang. Selain itu, kegiatan magang ini juga bertujuan mencari alternatif pemecahan masalah yang mungkin ditemukan terutama masalah yang berhubungan dengan pemangkasan.

\section{BAHAN DAN METODE}

Kegiatan magang dilakukan di Karanganyar, Jawa Tengah. Kegiatan magang dilakukan pada bulan Februari sampai dengan Juni 2011. Kegiatan penelitian dilakukan dengan metode kerja aktif dengan mengikuti berbagai kegiatan yang dilakukan di kebun, pengumpulan data primer dan data sekunder. Metode kerja aktif dilakukan dengan bekerja sebagai Karyawan Harian Lepas (KHL) selama satu bulan, pendamping mandor selama satu bulan, dan pendamping kepala bagian kebun (administrator) selama dua bulan. Kegiatan yang dilakukan dapat bersifat fleksibel sesuai dengan kegiatan yang berlangsung di kebun.

Pengumpulan data primer diperoleh dari hasil pengamatan lapang selama mengikuti pelaksanaan kegiatan di kebun dengan aspek pemangkasan serta hasil wawancara dan diskusi langsung dengan karyawan dan staff, sedangkan data sekunder didapat dari hasil laporan dan arsip kebun. Data sekunder yang diperlukan dapat berupa data mingguan ataupun bulanan, meliputi luas area, topografi, organisasi dan manajemen kebun, luas pangkasan pertahun, serta kebutuhan tenaga.

Pengamatan lapang dilakukan pada 10 tanaman contoh dengan umur pangkasan yang berbeda serta beberapa kali ulangan. Data hasil pengamatan lapang difokuskan pada kegiatan sebelum pemangkasan, pada saat pemangkasan, dan setelah pemangkasan. Pengamatan sebelum pemangkasan meliputi pengamatan terhadap tinggi dan diameter bidang petik serta persentase pucuk burung, sedangkan pengamatan pada saat pemangkasan meliputi tinggi dan diameter bidang pangkasan, biomassa serasah pangkasan, persentase kerusakan cabang, komposisi batang, kebutuhan tenaga pemangkas, jenis pangkasan, dan luas areal yang dipangkas. Pengamatan setelah pemangkasan yaitu pertumbahan tunas. Pengolahan data dilakukan dengan menggunakan uji $t$-student dengan taraf nyata 5\%. 


\section{HASIL DAN PEMBAHASAN}

Waktu Pangkas

Waktu pangkas merupakan saat yang tepat untuk dilaksanakannya pemangkasan agar hasil pangkasan optimal. Beberapa hal yang mempengaruhi waktu pangkas antara lain daur pangkas, kondisi tanaman, iklim, dan ketinggian tempat. Waktu yang tepat untuk melaukan pemangkasan adalah pada saat akhir musim penghujan karena pada saat itu frekuensi hujan tidak terlalu besar dan curah hujannya sesuai dengan yang dibutuhkan tanaman. Apabila pemangkasan dilakukan pada musin kemarau akan berdampak fatal pada tanaman terutama pada tanaman yang berada di dataran rendah.

\section{Daur Pangkas}

Daur pangkas merupakan jangka waktu antara pangkasan yang dahulu dengan pangkasan berikutnya dalam blok yang sama dan biasanya dinyatakan dalam tahun. Penentuan daur pangkas dipengaruhi oleh beberapa faktor, antara lain ketinggian kebun, sistem petik, pengelolaan tanaman, dan tinggi pangkasan sebelumnya.

Semakin tinggi letak suatu kebun maka daur pangkas akan semakin lama, hal ini disebabkan suhu dan intensitas matahari pada daerah dataran tinggi lebih rendah sehingga menyebabkan pertumbuhan tanaman semakin lambat (setyamidjaja,2000). Apabila pengelolaan tanaman baik pada kebun yang ketinggian pangkasannya rendah dan pemanenan dengan sistem petikan berat, maka daur pangkas kebun tersebut cinderung makin panjang. Perkebunan di Karanganyar terletak pada ketinggian 700-1300 m dpl menerapkan daur pangkas 3-4 tahun dengan sistem petikan medium.

Tabel 1. Daur Pangkas Tiga Blok di Kebun Rumpun Sari Kemuning

\begin{tabular}{|c|c|c|c|c|}
\hline Blok & $\begin{array}{l}\text { Luas } \\
\text { Area }\end{array}$ & $\begin{array}{c}\text { Waktu } \\
\text { Pemangkasan } \\
\text { Sebelumnya }\end{array}$ & $\begin{array}{c}\text { Waktu Pangkas } \\
\text { Berikutnya } \\
\text { Rencana Realisasi }\end{array}$ & $\begin{array}{c}\text { Daur } \\
\text { Pangkas } \\
\text { (bulan) }\end{array}$ \\
\hline A15 & 14.87 & Mei-07 & Jan-11 Feb-11 & 45 \\
\hline B04 & 14.15 & Nov-07 & Mei-11 & 42 \\
\hline B05 & 16.05 & Mei-07 & Mar-11 & 47 \\
\hline
\end{tabular}

Sumber: Arsip Kantor

\section{Tinggi Tanaman}

Tanaman teh yang semakin tinggi dengan tingkat kerapatan yang semakin tinggi pula akan menyulitkan dalam proses pemetikan. Hal ini akan menyebabkan penurunan produksi sehingga target produksi tidak bisa dicapai. Pemangkasan biasanya dilakukan setelah tanaman mencapai $120 \mathrm{~cm}$. Hasil pengamatan ketinggian dan diameter bidang petik pada dua blok pangkasan yang ada di kebun Rumpun Sari Kemuning adalah sebagai berikut:

Tabel 2. Tinggi dan Diameter Bidang Petik Sebelum Pemangkasan

\begin{tabular}{|c|c|c|c|c|c|}
\hline \multirow[b]{2}{*}{ Blok } & \multicolumn{2}{|l|}{ Umur } & \multicolumn{2}{|c|}{ tinggi bidang petik } & \multirow{2}{*}{ Diameter } \\
\hline & $\begin{array}{c}\text { Pangkas } \\
\text { (bulan) }\end{array}$ & $\mathrm{N}$ & & Standar & \\
\hline B04 & 42 & 6 & 108,45 & 120 & 124,61 \\
\hline B05 & 59 & 6 & 124,73 & 120 & 117,06 \\
\hline & Rata-rata & & 116,59 & & 120,835 \\
\hline
\end{tabular}

Sumber: Pengamatan lapang

Pada tabel dapat dilihat bahwa pelaksanaan pemangkasan di blok B04 dilakukan pada saat tinggi tanaman belum mencapai $120 \mathrm{~cm}$, sedangkan pada blok B05 dilakukan pada tanaman yang tingginya ratarata mencapai $124,73 \mathrm{~cm}$. tingkat kerapatan blok B04 lebih tinggi dibandingkan blok B05. Menurut rencana pemangkasan seharusnya blok B04 belum masuk waktu pangkas, namun dikarenakan kondisi kebun yang menyulitkan pemanen mengambil pucuk maka diambil tindakan pemangkasan.

\section{Persentase Pucuk Burung}

Persentase pucuk burung pada tanaman akan semakin tinggi seiring dengan semakin tuanya umur tanaman sehingga periode burung juga semakin lama. Periode burung merupakan lamanya suatu pucuk berada dalam posisi dorman sehingga pertumbuhan pucuk baru juga semakin lama. Pada saat kondisi pucuk burung tinggi maka kadar pati di akar semakin banyak karena pada saat ini tanaman mengakumulasikan hasil fotosintesisnya di akar (Pusat Penelitian Teh dan Kina, 2006). Berikut merupakan hasil pengamatan persentase pucuk burung pada dua blok di kebun Rumpun Sari Kemuning:

Tabel 3. Persentase Pucuk Burung

\begin{tabular}{ccc}
\hline Blok & Umur Pangkasan & $\begin{array}{c}\text { Persentase Pucuk } \\
\text { Burung }\end{array}$ \\
\hline B04 & 42 & $74,3^{\text {(II) }}$ \\
B05 & 59 & $76,2^{\text {tn }}$ \\
\hline & Rata-rata & 75,25 \\
\hline
\end{tabular}

Sumber: Hasil pengamatan lapang 
Ket : ${ }^{\mathrm{tn})}=$ Hasil uji t-student tidak berbeda nyata
pada taraf $5 \%$

Pemangkasan sebaiknya dilakukan pada saat persentase pucuk burung mencapai $70 \%$. Pada tabel dapat dilihat bahwa persentase kedua blok lebih dari $70 \%$ dan hasil uji t-student juga menunjukkan bahwa persentase kedua blok tidak berbeda nyata sehingga secara umum pemangkasan yang dilakukan di kebun Rumpun Sari Kemuning telah sesuai meskipun menurut umur pangkasan pada blok B04 seharusnya belum dilakukan pemangkasan.

\section{Luas Area Pemangkasan}

Perkebunan Rumpun Sari Kemuning menetapkan luas area pemangkasan sebesar 30\% per tahun dari total luas area TM yang dibagi dalam dua semester. Waktu pangkas semester I pada bulan Februari sampai Juni (60-75 \% target setahun) dan semester II pada bulan September sampai November (25-40 \% target setahun). Namun sebelum tahun 2002 penetapan luas area pemangkasan yakni sebesar 20\%. Data realisasi luas area pemangkasan di kebun Rumpun Sari Kemuning menunjukkan bahwa pelaksanaan pemangkasan belum sesuai dengan ketentuan yang ditetapkan kebun yaitu sebesar 30\% pertahun dari total luas area TM. Hal ini terjadi karena pada saat pelaksanaannya waktu yang dibutuhkan para pemangkas melebihi waktu yang ditargetkan kebun sehingga pelaksanaan pangkas pada blok lain juga tertunda. Penundaan ini berakibat luas area pemangkasan lebih kecil dari target yang direncanakan sehingga ketentuan yang ditetapkan belum dapat terpenuhi.

\section{Alat Pangkas}

Alat pangkas yang biasa digunakan
antara lain gergaji pangkas ataupun menggunakan sabit pangkas dan alat ukur. Pelaksanaan pemangkasan di kebun Rumpun Sari Kemuning menggunakan sabit pangkas. Alat-alat pangkas yang digunakan harus dimiliki sendiri oleh para pemangkas. Apabila menggunakan gergaji pangkas pengerjaan pemangkasan akan membutuhkan waktu lebih lama sehingga pelaksanaan rencana pemangkasan berikutnya juga tertunda. Pemotongan cabang/ranting yang berukuran lebih kecil dari ibu jari (diameter $<2 \mathrm{~cm}$ ) digunakan gaet pangkas, sedangkan cabang/ranting yang berukuran lebih besar (diameter $\geq 2 \mathrm{~cm}$ ) digunakan gergaji pangkas (Setyamidjaja, 2000). Sabit pangkas yang digunakan harus tajam agar batang/cabang yang dipangkas tidak rusak/pecah.

\section{Jenis Pangkasan}

Jenis pangkasan yang dilakuakan di kebun Rumpun Sari Kemuning adalah pangkasan bersih yakni pangkasan dengan bidang pangkas yang rata, tetapi pada bagian tengahnya agak rendah (ngamangkok), dengan membuang semua ranting-ranting kecil yang berukuran diameter kurang dari $1 \mathrm{~cm}$ untuk memperbaiki percabangan. Pembentukan bidang pangkas yang agak rendah bagian tengahnya dikarenakan tunas yang tumbuhnya ke atas umumnya pertumbuhannya lebih cepat daripada tunas yang tumbuhnya ke samping.

Luka pangkas pada cabang pangkasan membentuk sudut $45^{\circ} \mathrm{C}$ dan menghadap ke arah dalam. Luka pangkas tersebut sebisa mungin tidak terlalu lebar dan tidak pecah/rusak. Apabila luka pangksan telalu lebar, dikhawatirkan penguapan pada luka pangkasan lebih tinggi sehingga tanaman menjadi kering. Pertumbuhan tunas pada cabang/ranting pangkasan yang rusak/pecah akan terganggu, karena jaringan pada cabang/ranting yang rusak/pecah akan mati sehingga zat pati pembentuk tunas tidak dapat berjalan lancar.

\section{Tinggi Pangkasan}

Tinggi pangkasan merupakan ketinggian bidang pangkas dari permukaan tanah samapi luka bekas pangkasan. Kebun Rumpun Sari Kemuning memetapkan standar ketinggian pangkas $55-65 \mathrm{~cm}$ dengan sistem pangkasan berjenjang. Pada sistem tersebut pemangkasan dilakukan dengan menaikkan tinggi pangkasan $\left(\begin{array}{ll} \pm 5 \mathrm{~cm}\end{array}\right)$ melebihi pangkasan sebelumnya. Berikut merupakan hasil pengamatan tinggi pangkasan yang dilakukan di kebun Rumpun Sari Kemuning:

Tabel 4. Tinggi Pangkasan Dua Blok pada Kebun Rumpun Sari Kemuning

\begin{tabular}{ccccc}
\hline Blok & $\begin{array}{c}\text { Umur Pangkas } \\
\text { (bulan) }\end{array}$ & \multicolumn{4}{c}{ Tinggi Pangkasan } & Diameter \\
\hline & 46 & 56,68 & 55 & 52,69 \\
A15 & 46 & 59,62 & 55 & 58,77 \\
B04 & 42 & 63,67 & 55 & 69,67 \\
B05 & 59 & 59,99 & & 60,37 \\
& Rata-rata & &
\end{tabular}

Sumber: Pengamatan langsung 
Pada tabel hasil pengamatan dapat dilihat bahwa ketinggian pangkasan pada ketiga blok melebihi standar yang telah ditetapkan oleh kebun. Hal ini mungkin dikarenakan para pemangkas lebih mementingkan kuantitas hasil pangkas sehingga kurang memperhatikan tentang ketinggian bidang pangkas.

\section{Tenaga Pemangkas}

Pemangkasan merupakan kegiatan yang tidak hanya membutuhkan tenaga, tetapi juga keterampilan dan kecekatan. Tenaga pemangkas kebun Rumpun Sari Kemuning bersifat borongan dengan upah Rp. 18.000,- per patok $\left(400 \mathrm{~m}^{2}\right)$. Satandar HK yang ditetapkan untuk pemangkasan adalah $0.04 \mathrm{ha} / \mathrm{HK}$.

Tabel 5. Kapasitas Kerja Pemangkas Perkebunan Rumpun Sari Kemuning

\begin{tabular}{|c|c|c|c|c|c|}
\hline \multirow[t]{2}{*}{ Blok } & \multirow{2}{*}{$\begin{array}{c}\text { Luas } \\
\text { Pangkasan }\end{array}$} & \multicolumn{2}{|c|}{ HK } & \multicolumn{2}{|c|}{$\begin{array}{c}\text { Prestasi Kerja } \\
(\text { ha/HK) }\end{array}$} \\
\hline & & Rencana & Realisasi & Standar & Riil \\
\hline A15 & 9,87 & 247 & 129 & 0,04 & 0,08 \\
\hline B04 & 14,15 & 354 & 168 & 0,04 & 0,08 \\
\hline B05 & 6,05 & 151 & 109 & 0,04 & 0,06 \\
\hline & Rata-rata & & & 0,04 & 0,07 \\
\hline
\end{tabular}

Sumber: Arsip Kantor

Pada tabel terlihat bahwa realisasi penggunaan $\mathrm{HK}$ lebih rendah dibandingkan dengan rencana kebutuhannya. Hal ini tentunya menguntungkan bagi pihak kebun karena tenaga yang dibutuhkan lebih sedikit sehingga dapat mengurangi biaya pemangkasan. Prestasi kerja para pemangkas juga lebih tinggi daripada standar yang ditentukan kebun. Para pemagkas lebih cinderung mengejar kuantitas hasil pangkasan. Hal ini seharusnya menguntungkan bagi pihak kebun karena selain biaya yang dikeluarkan lebih kecil, waktu penyelesaian pemangkasan bisa lebih cepat. Namun dalam pelaksanaan di lapangan terkadang pengerjaan pemangkasan pada suatu blok melebihi waktu yang ditentukan oleh kebun. Hal ini dikarenakan keterbatasan tenaga pemangkas. Biasanya tenaga pemangkas sehari sekitar 6-9 orang, tetapi apabila ada acara yang menyangkut sosial budaya masyarakat sekitar, jumlah tenaga pemangkas bisa berkurang drastis sehingga waktu pelaksanaan pemangkasan bertambah lama.

Keterampilan Pemangkas Berdasarkan Lama Kerja
Hasil pada tabel tersebut menunjukkan bahwa persentase kerusakan cabang oleh para pemangkas yang bekerja < 10 tahun lebih tinggi dibandingkan dengan para pemangkas yang telah bekerja $\geq 10$ tahun. Hal ini menunjukkan bahwa tenaga pemangkas yang bekerja $\geq 10$ tahun memiliki tingkat keterampilan yang tinggi dibandingkan dengan tenaga yang bekerja $<10$ tahun sebagai pemangkas. Meskipun perbedaan pengalaman kerja menunjukkan perbedaan dalam segi keterampilan memangkas, tetapi berdasarkan uji t-student hal tersebut tidak memberikan perbedaan yang nyata. Hasil pada tabel menunjukkan bahwa pemangkas yang bekerja $\geq$ 10 tahun memiliki tingkat ketelitian yang lebih baik dari pada pemangkas yang bekerja $<10$ tahun. Hal ini dapat dilihat dari persentase komposisi batang hasil pemangkasan, pemangkas yang bekerja $\geq 10$ tahun persentase cabang hasil pemangkasan yang berukuran $<2 \mathrm{~cm}$ lebih rendah dibandingkan dengan pemangkas yang bekerja < 10 tahun. Namun, secara umum kedua kriteria tenaga pemangkas memiliki presentase komposisi cabang yang berukuran $\geq 2 \mathrm{~cm}$ lebih besar dibandingkan cabang pangkasan yang berukuran $<2 \mathrm{~cm}$. Hal ini membuktikan tenaga pemangkas kurang memperhatikan ketelitian tetapi lebih mengejar kuantitas.

Tabel 6. Persentase Kerusakan Cabang Berdasarkan Lama Kerja Pemangkas

\begin{tabular}{ccccc}
\hline Lama kerja & $\begin{array}{c}\sum \text { Tenaga } \\
\text { Pemangkas }\end{array}$ & $\begin{array}{c}\% \\
\text { kerusakan }\end{array}$ & $\begin{array}{c}\text { Komposisi } \\
\text { batang (\%) }\end{array}$ \\
\hline$\geq 10$ tahun & 5 & $12,65^{\text {tn }}$ & 28,92 & 71,08 \\
$<10$ tahun & 5 & $14,94^{\text {tn }}$ & 22,62 & 77,58 \\
\hline
\end{tabular}

Sumber: Hasil pengamatan lapang

Ket $:{ }^{\text {tn) }}=$ Hasil uji t-student tidak berbeda nyata pada taraf $5 \%$

\section{Keterampilan Berdasarkan Usia}

Tabel 7. Persentase Kerusakan Cabang Berdasarkan Usia Pemangkas

\begin{tabular}{|c|c|c|c|c|}
\hline \multirow{2}{*}{ Usia } & \multirow{2}{*}{$\begin{array}{c}\sum \text { Tenaga } \\
\text { Pemangkas }\end{array}$} & \multirow{2}{*}{$\begin{array}{c}\% \\
\text { kerusakan }\end{array}$} & \multicolumn{2}{|c|}{$\begin{array}{l}\text { Komposisi } \\
\text { batang }(\%)\end{array}$} \\
\hline & & & $\begin{array}{l}\geq 2 \\
\mathrm{~cm}\end{array}$ & $\begin{array}{l}<2 \\
\mathrm{~cm}\end{array}$ \\
\hline$\geq 50$ tahun & 5 & $13,13^{\mathrm{tn})}$ & 29,09 & 70,91 \\
\hline$<50$ tahun & 5 & $11,05^{\mathrm{tn})}$ & 18,26 & 81,88 \\
\hline
\end{tabular}


Pada tabel tersebut dapat dilihat bahwa tingkat kerusakan cabang pangkasan yang dilakukan oleh tenaga pemangkas yang berusia $\geq$ 50 tahun lebih tinggi dibandingkan dengan tenaga pemangkas yang berusia $<50$ tahun. Hal ini menunjukkan bahwa tenaga pemangkas yang berusia $\geq 50$ tahun kurang terampil dibandingkan dengan tenaga pemangkas yang berusia $<50$ tahun. Meskipun demikian, hasil pengujian tidak menunjukkan perbedaan nyata antara dua criteria usia pemangkas tersebut. Hasil pengamatan terhadap komposisi batang pada kedua kriteria pemangkas menunjukkan bahwa keduanya meninggalkan batang yang berukuran $<2 \mathrm{~cm}$ lebih banyak dibandingkan batang yang berukuran $\geq 2 \mathrm{~cm}$. Padahal pembuangan cabang yang kecil pada pemangkasan bersih dapat memperbaiki percabangan. Namun pada tabel terlihat bahwa persentase batang $<2 \mathrm{~cm}$ yang dilakukan pemangkas yang berusia $\geq 50$ tahun lebih rendah dibandingkan dengan tenaga yang berusia $<50$ tahun, hal ini menunjukkan bahwa pemangkas yang berusia $\geq 50$ lebih teliti jika dibandingkan dengan tenaga yang berusia $<50$ tahun. Apabila dilihat dari persentase komposisi cabang seluruh pemangkas, secara umum persentase cabang yang berukuran $<2 \mathrm{~cm}$ lebih tinggi dari persentase cabang yang berukuran $\geq 2$ $\mathrm{cm}$. Jadi, dapat dikatakan bahwa tenaga pemangkas baik yang berusia $\geq 50$ tahun maupun $<50$ kurang teliti dalam membuang cabangcabang kecil.

\section{Keterampilan Berdasarkan Pendidikan}

Tabel 8 menunjukkan bahwa persentase kerusakan cabang akibat pemangkasan yang dilakukan tenaga yang tidak lulus SD lebih tinggi dibandingkan dengan tenaga pemangkas yang mempunyai pendidikan minimal tingkat SD. Hal ini menunjukkan bahwa tenaga yang berpendidikan minimal SD memiliki keterampilan yang lebih tinggi dibandingkan dengan tenaga yang tidak tamat SD mekipun hasilnya tidak berbeda nyata. Tingkat ketelitian pemangkas dapat dilihat juga dari komposisi batang pada perdu yang dipangkasnya. Batang yang berukuran kecil sebaiknya dipangkas untuk memperbaiki percabangan. Hasil pengamatan menunjukkan bahwa persentase batang yang berukuran $<2 \mathrm{~cm}$ hasil pangkasan yang dilakukan tenaga pemangkas yang minimal berpendidikan SD lebih tinggi dari pemangkas yang tidak tamat SD, hal ini menunjukkan bahwa pemangkas yang tidak lulus SD tingkat ketelitiannya justru lebih tinggi. Secara umum dapat dilihat bahwa komposisi batang kedua kriteria tenaga pemangkas menunjukkan bahwa persentase cabang pangkasan yang berukuran $\geq 2 \mathrm{~cm}$ lebih tinggi dibandingkan cabang pangkasan yang berukuran $<2 \mathrm{~cm}$, hal ini membuktikan bahwa para tenaga pemangkas kurang teliti pada hasil pangkasannya.

\begin{tabular}{|c|c|c|c|c|}
\hline Tabel & $\begin{array}{l}\text { 8. Persentase } \\
\text { berdasarkar } \\
\text { pemangkas }\end{array}$ & $\begin{array}{l}\text { kerusa } \\
\text { tingk }\end{array}$ & $\begin{array}{l}\text { kan } \\
\text { at pe }\end{array}$ & $\begin{array}{l}\text { cabang } \\
\text { didikan }\end{array}$ \\
\hline \multirow[t]{2}{*}{ Pendidikan } & $\sum$ Tenaga & \% kerusakan & \multicolumn{2}{|c|}{$\begin{array}{l}\text { Komposisi } \\
\text { batang (\%) }\end{array}$} \\
\hline & Pemangkas & & $\geq 2 \mathrm{~cm}$ & $<2 \mathrm{~cm}$ \\
\hline $\begin{array}{c}\text { SD } \\
\text { Tidak }\end{array}$ & 5 & $11,93^{\text {tn) }}$ & 25,43 & 74,57 \\
\hline Tamat SD & 5 & $17,35^{\text {tn) }}$ & 28,11 & 71,89 \\
\hline
\end{tabular}

Sumber: Hasil pengamatan lapang

Ket $:{ }^{\mathrm{tn})}=$ Hasil uji t-student tidak berbeda nyata pada taraf $5 \%$

\section{Pertumbuhan Tunas}

Pertumbuhan tunas pucuk sangat mempengaruhi gilir petik tanaman teh. Semakin tinggi tingkat pertumbuhan teh, semakin pendek gilir petiknya. Selain itu dilakukan juga pemangkasan untuk mempermuda cabang-cabang agar bertahan pada fase vegetatif. Umumnya tunas mulai pecah setelah berumur 21 hari setelah pemangkasan. Pengamatan pertumbuhan tunas dilakukan pada dua blok yaitu blok A15 dan blok B05. Kedua blok berada pada ketinggian $1100 \mathrm{~m}$ dpl dengan jenis klon yang sama yaitu TRI 2025.

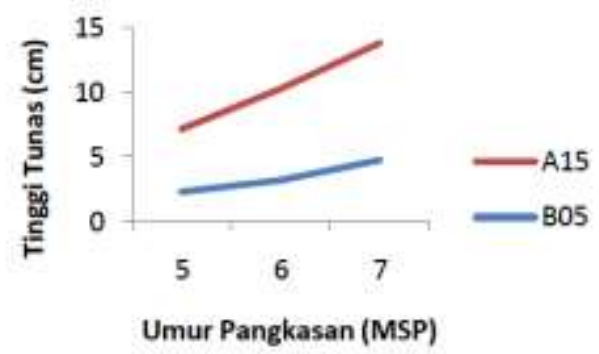

Gambar 1. Grafik Pertumbuhan Tunas Dua Blok di Kebun Rumpun Sari Kemuning

Pertumbuhan tunas dapat dipengaruhi beberapa faktor antara lain kesuburan tanah, suhu dan intensitas penyinaran. Grafik tersebut menunjukkan bahwa perumbuhan tunas pada umur 5,6,7 minggu setelah pemangkasan (MSP) pada blok A15 lebih cepat dibandingkan dengan blok B05. Pada blok A15 ada beberapa tunas yang tingginya sudah $15 \mathrm{~cm}$, sedangkan pada blok B05 belum seharusnya pertumbuhan tunas lebih cepat karena cadangan makanan tanaman di Blok BO5 lebih banyak tetapi hasil pengamatan menunjukkan sebaliknya. Hal ini mungkin dipengaruhi oleh perbedaan umur pangkasan. 
Umur pangkasan pada Blok B05 lebih lama dibandingkan Blok A15.

\section{Pengelolaan Sisa Pangkasan}

Areal pangkasan yang terbuka akan menyebabkan peningkatan penguapan tanah sehingga kelembaban tanah akan menurun, hal ini dapat menghambat aktivitas penyerapan air dan hara. Oleh karena itu cabang/ranting dan daun pangkasan diupayakan untuk tidak ke luar dari areal pangkasan dan dimanfaatkan untuk menambah bahan organik dan unsur hara tanah. Menurut penelitian Johan (2003), serasah pangkasan teh $23.750 \mathrm{~kg} / \mathrm{ha}$, terdiri dari cabang/ranting $77 \%$ dan daun $23 \%$, setara dengan $235 \mathrm{~kg}$ urea $+48 \mathrm{~kg}$ TSP $+106 \mathrm{~kg} \mathrm{ZA} / \mathrm{ha}$. Biomassa serasah pangkasan yang diamati di kebun Rumpun Sari Kemuning adalah sebagai berikut:

Tabel 9. Serasah Sisa Pangkasan Dua Blok di Kebun Rumpun Sari Kemuning

\begin{tabular}{ccc}
\hline Blok & Luas Areal Pangkas (ha) & $\begin{array}{c}\text { Serasah Pangkasan } \\
(\mathrm{kg} / \mathrm{ha})\end{array}$ \\
\hline A15 & 9.87 & 25125 \\
B04 & 14.15 & 24230 \\
B05 & 6.05 & 23125 \\
& Rata-rata & 24160 \\
\hline
\end{tabular}

Sumber: Pengamatan langsung

Data pada tabel tersebut dapat lihat bahwa biomassa rata-rata mencapai $24160.1 \mathrm{~kg} / \mathrm{ha}$. Apabila serasah-serasah pangkasan tidak diambil dari kebun maka hara yang bertambah setara dengan $239.7 \mathrm{~kg}$ urea $+48.96 \mathrm{~kg}$ TSP $+108.12 \mathrm{~kg}$ ZA/ha. Hal ini berarti dalam 4 tahun ke depan penyediaan kebutuhan unsur-unsur hara khususnya $\mathrm{N}$ dan $\mathrm{P}$ dapat dibantu oleh sisa-sisa pengkasan yang telah terdekomposisi tersebut. Selain itu, penelitian yang dilakukan Widayat (2008) menyebutkan bahwa sisa pangkasan yang digunakan sebagai mulsa pada takaran 10, 20, 30 ton/ha dapat meningkatkan produksi pucuk dan menekan pertumbuhan gulma. Kayu sisa pangkasan yang ada di kebun Rumpun Sari kemuning biasanya diambil oleh penduduk, padahal sebagian besar serasah merupakan kayu. Namun, hal ini bagi pihak kebun dianggap tidak terlalu merugikan karena secara tidak langsung para pengambil kayu telah membantu pihak kebun dalam kegiatan beres cabang.

\section{Tingkat Produksi}

Pemangkasan secara umum dilakukan bila tingkat produksi tanaman menurun. Hal ini dikarenakan semakin tua umur tanaman, maka umumnya pertumbuhan akan beralih dari fase vegetatif ke fase generatif sehingga pertumbuhan pucuk menurun. Berikut merupakan hubungan produksi dengan umur pangkas tanaman teh:

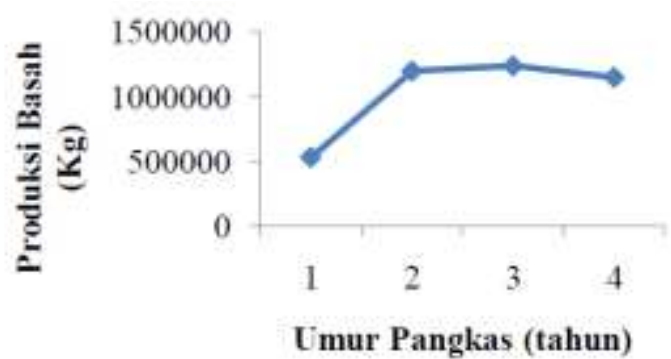

Gambar 2. Grafik Produktivitas Tanaman Teh di Tiga Blok di Kebun Rumpun Sari Kemuning

Produktivitas tanaman meningkat seiring dengan bertambahnya umur pangkas pada tahun pertama sampai ketiga. Produktivitas maksimal berada pada umur tiga tahun setelah pemangkasan kemudian mulai menurun pada tahun keempat setelah pangkas. Hal ini juga terlihat dari grafik produksi pada dua blok di kebun Rumpun Sari Kemuning. Penurunan produktivitas ini dapat disebabkan karena beberapa hal antara lain ketinggian bidang petik yang menyulitkan pemetik memanen pucuk dan pertumbuhan pucuk lambat sehingga jumlah pucuk muda sedikit.

\section{KESIMPULAN}

Pelaksanaan pemangkasan di kebun Rumpun Sari Kemuning sudah cukup baik. Ketentuan yang di tetapkan kebun sudah sesuai dengan pedoman umum pemangkasan meskipun dalam pelaksanaannya tidak terlepas dari beberapa hal yang kurang sesuai, misalnya pergeseran gilir pangkas serta tinggi

pangksan yang belum sesuai dengan ketentuan. Pergeseran gilir pangkas yang disebabkan penambahan waktu pemangkasan diblok lain sehingga pengerjaan pemangkasan tidak sesuai rencana yang dibuat. Tenaga pemangkas biasanya mengejar kuantitas hasil, sehingga para pemangkas tersebut terkadang kurang memperhatikan tentang ketinggian bidang pangkas maupun tingkat kerusakannya. Tenaga yang telah lama bekerja sebagai pemangkas umumnya memiliki keterampilan yang lebih tinggi, sehingga tingkat kerusakan pada cabang 
pangkasan relatif rendah dibandingkan dengan tenaga pemangkas baru.

Pertumbuhan tunas pada dua afdeling yang diamati menunjukkan bahwa pertumbuhan tunas pada afdeling OA lebih cepat jika dibandingkan dengan afdeling OB. Hal ini disebabkan karena intensitas penyinaran afdeling OA lebih banyak jika dibandingkan dengan afdeling OB, selain itu juga tingkat kesuburan tanah afdeling OA lebih baik. Pengelolaan sisa pangkasan juga cukup baik, hanya saja perlu dilakukan beres cabang setelah pemangkasan agar tidak menghambat pertumbuhan pucuk nantinya.

Melalui kegiatan magang mahasiswa dapat lebih memahami proses kerja nyata di lapang serta dapat meningkatkan kemampuan dalam hal pengelolaan tanaman teh, baik pada aspek teknis maupun menejerial.

\section{DAFTAR PUSTAKA}

Bina UKM. 2010. Peluang usaha perkebunan teh. http://binaukm.com. [19 September 2010].

Direktorat Jenderal Perkebunan. 2011. Luas Areal dan Produksi Perkebunan Seluruh Indonesia Menurut Pengusahaan. http://www.ditjenbun.deptan.go.id. [5 Juni 2011].

Food and Agriculture Organization. 2011. Tea. http://faostat.fao.org. [6 Juni 2011].

Johan, M.E. 2003. Pemanfaatan Serasah Pangkasan Untuk Menunjang Peningkatan Produksi Pucuk Bagi Kebun Teh Organik. Prosiding Simposium Teh Nasional. Pusat Penelitian The dan Kina. Gambung. 163166.

Pusat Penelitian Teh dan Kina. 2006. Petunjuk Kultur Teknis Tanaman Teh. Edisi ketiga. Gambung.

Setyamidjaja, D. 2000. Budidaya dan Pengolahan Pasca Panen Tanaman Teh. Kanisius. Yogyakarta.

Walpole, R.E. 1993. Pengantar Statiistika. Edisi ke-3. PT Gramedia Pustaka Utama. Jakarta.

Widayat, W. 2008. Pengaruh penggunaan mulsa terhadap fluktuasi populasi dan intensitas serangan Empoasca. Jurnal Penelitian The dan Kina 11 (3): 45-57. 